\title{
Government Management Mechanism and Innovation Path in the Perspective of Low Carbon Economy
}

\author{
Xiaoyan Liu \\ Department of Political Theory Teaching, Nanyang Institute of Technology, Nanyang, China
}

251449292@qq.com

Keywords: Government management; Low carbon economy; Mechanism innovation; Innovation path

\begin{abstract}
The effects of environmental variables, government management and improve the efficiency of the need to the development of low carbon economy idea into the government management system, through the improvement of management strategy, provide urgently needed products and services for the society. Taking the low-carbon economy perspective, firstly analyzes the relationship between low carbon economy and government administration, and then taking this as the foundation, discuss and give the management mechanism and innovation path of government from the perspective of low carbon economy.
\end{abstract}

\section{Introduction}

In the course of the transformation of the economic model of human society, it is accompanied by the reorientation of the government's role and the transformation of the government's management mechanism. In the field of low carbon economy, play the role of the government and the role of play, by the widespread concern from all walks of life, is to appear "participatory countries assisted the identity, or to" protect "the national leading role exist? Actually, under the influence of environmental variables, improve the efficiency of the government need the development of the concept of low carbon economy included in the government management system, through the improvement of management strategy, for the society to provide urgently needed products and services, so as to highlight the government's strategic position [1]. This is because, under the framework of economics, expect companies or the people in the lower the efficiency and quality of life, take the initiative to reduce carbon emissions then the full realization of low carbon economy is unrealistic, need the government from the legal, policy and technical level to be a strong push. From the perspective of low carbon economy, the relationship between low carbon economy and government management is analyzed. Then, the government management mechanism and innovation path of low carbon economy are discussed and given.

\section{The Relationship between Low Carbon Economy and Government Management}

Government Management Should Play an Important Role. Under the influence of environmental variables, countries all over the world pay great attention to the development of low-carbon economy, which is not only related to energy security and technological innovation, but also lead to the revolution in the way of life. And in order to reduce carbon emissions and strive to have more right to speak in the world, the government should be in its management objectives and low carbon economic convergence synthetic together at the same time, the maximum play the leading role. Because of low carbon economy is a systematic concept, related to the low carbon industry, low carbon technology, low carbon city, low carbon life a series of content, any country in the development of low carbon economy to comprehensive understanding of the economic system, regional system, all kinds of social organizations and individuals, and in the government's participation and leading to ensure information symmetry and adequacy [2].

China's Development of Low Carbon Economy Requires Government Management Innovation. China's current ongoing large-scale construction, transportation and other infrastructure 
construction, has made significant progress in building, also produced a large amount of energy consumption, not only greatly reduce the stock of natural resources, also in a certain extent, affected the people's production and living quality. In fact, the sustainable development of any economy can not be a long time to make a simple reproduction of conventional technology, both need to be through technical innovation and management innovation, to minimize the consumption of energy [3].

Low Carbon Economy and Politics of Convergence. "Political convergence" word first appeared in the works of Anthony Giddens and published in 2009, the climate change politics "and that is climate change policy" in a positive way and other value concept, political goals overlap together degree. "In the book, the author believes that climate change policy should be to have obvious innovation and full of vitality, and its ability to get broad support from the public, the key factor is the "political convergence". Actually, in response to climate change, human society introduced a series of important measures, development of low carbon economy is ranked one of the, the and technology and Economic Association Limited, but with the political and institutional is closely related to economic development paradigm asked the government to make more efforts [4] to this end. Since entering the 21st century, some western developed countries has completed the deployment of low carbon economic development model, hoping in the future international competition highlights advantages; other countries especially developing countries such as China, have gradually realized the refused to low carbon economic crisis may lead to irreversible and began for low carbon economy development framework into at the institutional, cultural and technological level. From this point of view, the development of low carbon economy is no longer an economic or technical problems, but increased to a high level of politics, becoming a new rule of regulation of the pattern of the world's development".

\section{Government Management Mechanism in the Process of Low Carbon Economy Development}

In the framework of economics, the impact of market transactions on the third party can be reduced and eliminated with the help of government behavior. In particular, the environmental problems, the market is often powerless, the need to complete the policy innovation and institutional design. Therefore, in order to solve low carbon economic development in the market failure, prominent political convergence of, need to give full play to the government function and innovation of government management mechanism. To this end, the government on the one hand, to vigorously promote the idea of "low carbon", on the other hand to develop and improve the relevant laws and regulations of low carbon, establish and perfect to promote low carbon economy financial policy system, makes use of the advantage in the process of industrialization boost low carbon economic development.

Establish and Improve the Financial System to Promote the Low Carbon Economy. Through analysis, it is known that, the government in the low-carbon economic development model plays a leading and security role, the role of re establishing the government decision to make overall planning on the road of the development of low-carbon economy, in addition to create a relaxed policy environment and the introduction of policies to improve, should also build and improve the financial system to promote the development of low carbon economy. For example, we should combine the current development status of China's low-carbon economy, by increasing financial support and tilt angle, constantly optimize the new economic paradigm of "input-output" structure; at the appropriate time through tax relief, financial subsidies and the government green purchase tax policy, provide the impetus and support for low carbon economy the operation; if necessary, to help the financial strength to the commercial financial institutions into the framework for the development of low carbon economy, through the role of the capital market to achieve a low carbon economy to support and promote; through perfecting the project financing of low carbon economy and mode of operation, promote the realization of sustainable development of low carbon economy.

Vigorously Promote the "Low Carbon" Concept, to Provide Much-needed Low-carbon Products and Services to the Community. The development practice of human society tells us that the government plays a unique role in promoting the social mainstream values and achieving social 
governance, and the development of low carbon economy also needs the support of the government to complete. Therefore, in the view of low carbon economy, the government should maximize the with the help of new media, traditional media, mobile Internet and instant communication tools, and vigorously promote the idea of "low carbon", improve the public awareness of the extent of "low carbon economy" concept and development model, and like to take this opportunity to change people's ideas, to maximize the elimination [5] the misunderstanding on the low carbon economy. In addition, we should cultivate and improve the social members of worrying about resources and the awareness of environmental protection, to the society provide much-needed low carbon products and services, to promote and encourage low-carbon life style and behavior, advocate including "low carbon" business enterprises, including all kinds of social organizations.

To Develop and Improve the Relevant Laws and Regulations Related to Low Carbon. In the process of building a low-carbon society, the government should re position the role, in order to economic development paradigm regulators, providers, the dominant status of the public in front of the public. Therefore, in order to adapt to the development of low carbon economy, the government needs to formulate relevant laws and regulations which are related to the low carbon economy and the development of low-carbon economy. The main work includes: the forward-looking and scientific perspective, the lack of development of low carbon economy laws and regulations to be added, so that a more complete system of laws and regulations, some areas can according to their own development of the actual development of local regulations and the maintenance of the ecological environment, to promote the healthy development of the social economy, the existing laws and regulations need to modify, supplement and improve the part, when, in accordance with the law and gradually be perfect, the low carbon economy gradually into the orbit of the rule of law.

\section{The Specific Content of Chinese Government Management Innovation in the Era of Low Carbon Economy}

Innovation of Government Management System. Since a long period of time, under the influence of the historical and realistic factors, took on the ecological environment and natural resources protection in China is the attitude of "strong government, weak society", in the management system, the effect of low carbon management is extremely limited, and human society's future development goals of unity [6]. In order to change this situation, the need to strengthen the reform and innovation of government management system, in order to enhance the ability of low carbon governance and governance efficiency. For example, we can consider the mode of government performance management of innovation, through the construction of the performance appraisal system of low carbon, prompting the government to take ecological protection and pollution control work as an important task to be completed; and, to timely construction procurement of low carbon, low carbon investment and investment system, strengthen the right to speak in the international affairs, enhance government execution of low carbon policy.

Innovation of Government Management Tools. All over the world, especially the practice of western developed countries shows that, in view of low carbon economy is the innovation of government management mechanism, need to rely on low carbon management tools and related technologies, has only strengthened the work to fundamentally improve the efficiency of government management innovation. In this process and need to recognize that the low carbon economy is a new economic development paradigm, with natural and social attribute of market and government departments for low carbon management tool of innovation need comprehensive consideration, the use of market instruments, construction system based on "command and control" technology, management and market means can be used. Only in this way can we improve the "green level" of the government decision-making process and improve the management effectiveness.

Government Management Concept Innovation. In recent years, with the advent of the efficient, clean, low carbon emissions for signs of "low carbon economy", management idea and the management thought of our country government caused a serious challenge, the original management 
concept has been unable to low carbon economy and spirit of the times and the requirements of the development to adapt, even in a certain extent has produced contradictions and conflicts. In this case, the government management needs to seek the concept of innovation. This is because the concept of innovation is the premise and foundation, the lack of ideological emancipation and the concept of innovation, the government management innovation will be difficult to start". From this angle, to the development of low carbon economy requirements oriented, in the value of the government management system and establish a comprehensive the value concept of "green and low-carbon development" is the era of low carbon economy, an important content of China's government management innovation, but also to provide the necessary value guidelines for government low carbon management practice.

Innovation of Government Management Function. In response to the call of the low carbon economy and the development of the practice of low carbon economy, due to the face of a new pattern of economic development, government management prone to fuzzy boundaries, the weak public service functions, local partition and functional segmentation serious phenomenon. In this case, the need to continue to highlight the role of the government's role in positioning, innovative management functions, in order to improve the efficiency of low carbon governance, of course, in this process and need to repositioning of government role, and the low carbon management functions to be reconstructed, through the position and role of government clearly in the low carbon economy management, fully draw the boundaries of government management, the pay and the market to follow the law of value, the return to the society to pay attention to person and natural harmony together, the homing of government to strengthen the supply of products and services, strengthen the government in social management and public service functions, establishes the low carbon economy from the perspective of government management functions of the market and social foundation.

\section{The Realization Path of Government Management Innovation Under the Background of Low Carbon Economy Development}

To Promote Innovation, Improve the Low Carbon Technology Development System. At present, the development of low carbon economy in China is still in its infancy, some work has just begun, there are still a lot of work is still in the preparation of the task. Based on the fact, the Chinese government should promote innovation, constructing target system complete, accurate action plan, to promote the comprehensive mechanism of management innovation mode, fully promote the improvement of low carbon economy and the development of the management efficiency. For example, the government should be leading, call and motivation of the research, development and promotion of low carbon technology, for the establishment of a set of clean energy and renewable energy, new energy in one of the diversified low carbon technology system; for example, the government should accurately estimate the scarcity of our country energy, reduce dependence on the international market, in the ways of low carbon economy bear more social responsibility. Therefore, it is necessary to focus on iron and steel, cement, electric power and other industrial sectors of transformation to low carbon technology, improve the production efficiency of process; emphasize and develop clean coal technology, the construction of low carbon demonstration power station, in collecting and storing carbon molecular technology to make more efforts.

Strengthen the Functions, Clear the Government's Goal Orientation. In order to promote the innovation of government management, better realize low carbon economy development goals, through co-ordination arrangements, the comprehensive integration of existing resources, and in the division of labor and cooperation with society, market, with the traditional media and new media publicity channels, publicity and promote the development of low carbon economy. At the same time, the government should further clarify the goal of positioning, through effective means to enhance public awareness of environmental protection and low carbon will, to guide its low carbon concept, practice low-carbon action. In addition, to strengthen the government's effective supervision on the market, ensure the supervision and control of the low carbon economic all-round, multi-level, with the 
international community to strengthen cooperation and exchanges in the process, the accumulation of experience in government management, improve management efficiency. For example, in terms of fiscal targets, the government should is committed to the development of clean energy, the transformation of traditional and backward production capacity at the same time, the financial capital of the overall arrangement, through the adjustment of the financial capital structure, fiscal expenditure can continue to energy-saving emission reduction areas tilt, through the integration of special funds of various departments, the maximum improve the efficiency of the use of funds, for the development of low carbon economy provides necessary and sufficient power.

Perfect Mechanism, Strengthen the Government's Leading Role. Mechanism construction is an important way of management innovation for our government to respond to a low carbon economy, not only to ensure the decision-making process of democratization, scientific and legal, but also after the decision, decision and decision full range collected information of low carbon economy, design scheme and filing of the corresponding to a new form of economy, after repeated comparison and analysis to select the optimal scheme. For example, in order to improve the efficiency of low carbon economic development, strengthen the government management innovation ability, introducing competition mechanism in the appropriate practical, enhance operational efficiency within the government organizations at the same time, to maximize the natural resources and social resources public products (services) of monopoly supply situation, reflects the social fairness and justice, promote the harmonious development of human life and the ecological environment. , of course, in this process and need to take government as the leading factor, and gradually change the coal dominated energy structure, play the social effect of the government in the nuclear, wind, hydro, solar and other low-carbon or carbon free energy.

\section{Conclusion}

Since the beginning of the new century, our society is facing all kinds of challenges related to environment and energy. In order to deal with a series of problems such as climate change and environmental pollution, the strategy of sustainable development of human society has been constructed, and all the countries in the world have been added to the framework of low-carbon economy. In fact, as a new type of economic development mode and life style, the development of low-carbon economy has achieved some success, but also face more difficulties and challenges. Especially in the key period of economic and social transformation in our country, should government management innovation mechanism, get rid of the original system, institutional barriers and seek for the thought and mode of government management in our country to improve the operational mechanism, improve the management efficiency.

\section{References}

[1] E. Ostrom. Governance of Public Affairs.(Shanghai Joint Publishing Company, China,2010).

[2] Intergovernmental Panel on climate change, the sixth assessment report on climate change [R].2011.

[3] Y.Z. Zhen. Urban studies, (2011) No.9, p.28.

[4] W.Y. Li: The Government Management Innovation Expo in the View of Low Carbon Economy (Theory), (2012) No.1, p.45.

[5] D. Huang and X. Hu. Journal of Huazhong University of Science and Technology (Social Science Education), (2010) No.4, p.100.

[6] M.K. Sheng,Q.Q. Zhu. Contemporary Economic Management, (2011) No.7, p.46. 